\title{
Teorías recientes de literacidad crítica para el inglés con fines específicos
}

\section{Contributions of Recent Theories of Critical Literacies to ESP}

\section{Teorias recentes de letramentos críticos para inglês para fins específicos}

\author{
Nara Hiroko Takaki* \\ *Universidade Federal de Mato Grosso do Sul (UFMS), Campo Grande, Mato Grosso \\ do Sul / Brasil \\ narahi08@gmail.com
}

https://orcid.org/0000-0001-8574-5842

\begin{abstract}
RESUMEN: Un currículum que forma alumnos problematizadores de significados contextuales fue la premisa para conciliar inglés instrumental, contingencias y metodología cualitativa en el curso de extensión "Taller de inglés instrumental: lecturas para el presente-futuro en el mundo contemporáneo", en el grado de Letras en una universidad pública. Es parte de una investigación más grande que explora las multialfabetizaciones de los graduandos desde una perspectiva de educación lingüística crítica. El curso destacó la construcción de sentidos por medio del lenguaje multimodal, reflexiones sobre diversidades complejas como expansión de la interpretación de los participantes.
\end{abstract}

PALABRAS-CLAVE: Literacidad crítica; inglés instrumental; contingencia; contexto.

\begin{abstract}
A curriculum which develops students' capacity to problematize contextual meanings was the premise to reconcile English for special purposes, contingencies and qualitative methodology in a community course named "Workshop of English for special purposes: readings for present-future in contemporary world", offered by a public university. This was part of a broader research, which examined under-graduate students' multiliteracies from the perspective of critical linguistic education. The course focused on meaning making through multimodal language, reflections upon complex diversities as expansion of the participants' interpretations.
\end{abstract}

KEYWORDS: Critical literacies; English for special purposes; contingencies; context. 


\begin{abstract}
RESUMO: Um currículo que forma alunos problematizadores de significados contextuais foi a premissa para conciliar inglês instrumental, contingências e metodologia qualitativa num curso de extensão denominado "Oficina de inglês instrumental: leituras para o presente-futuro em mundo contemporâneo", oferecido em uma universidade pública. É parte de uma pesquisa maior que investiga os multiletramentos dos graduandos na perspectiva de educação linguística crítica. O curso focalizou a construção de sentidos por meio de linguagem multimodal, reflexões sobre diversidades complexas como expansão da interpretação dos participantes.
\end{abstract}

PALAVRAS-CHAVE: Letramentos críticos; Inglês instrumental; Contingência; Contexto.

\title{
1 Introducción
}

La concepción de lo que se entiende por inglés con fines específicos (IFE) viene sufriendo revisiones. Actualmente, la noción de enseñanza de IFE ha experimentado nuevas demandas, es decir, la comprensión de lo que se puede entender por intercambio de ideas y realización de tareas, entre otras. La renegociación de sentidos requiere indagar el concepto de lenguaje adoptado y sus implicaciones en la formación de ciudadanos. El objetivo de este artículo es relatar una experiencia de enseñanza desarrollada en un curso de extensión de IFE que concilia el trabajo profesional con el uso de textos seleccionados de acuerdo con las necesidades de un grupo de aprendices/ participantes provenientes de diferentes grados. El trabajo de la lengua inglesa se desarrolló de manera integradora y contextualizada y promovió la capacidad crítico-interpretativa de los participantes.

El diseño y la implementación de ese curso se fundamentaron en la concepción de IFE elaborada por Hutchinson y Waters (1987) y DudleyEvans y Saint John (1998). Los primeros teóricos conciben el IFE como una actitud en relación a la enseñanza y aprendizaje de la lengua inglesa en que las decisiones sobre contenido y metodología se basan en los motivos del estudiante para aprender inglés. Corroborando tales teóricos, Dudley-Evans y Saint John (1998) complementan que el IFE no necesariamente debe estar relacionado a una única disciplina específica, aceptando la inclusión de otras disciplinas, haciendo uso de metodologías diferentes de aquellas que normalmente se adoptan en cursos regulares de enseñanza de inglés y pudiendo ser destinado o no a un grupo de determinada franja etaria. El curso también se orientó por las teorías recientes de literacidad, presupuestos que se discutirán posteriormente y que hacen parte de un proyecto nacional 
de literacidad del cual la autora de este artículo hace parte. En el curso que aquí se detalla, se eligió la noción de lenguaje como un proceso dinámico, contradictorio y complejo, según nos presenta Bakhtin (1999).

Un cambio visible en la visión de Pennycook (2010), Canagarajah (2008, 2014), entre otros teóricos, se debe al hecho de que el escenario del mundo contemporáneo ha revelado formas complejas interconectando diferentes identidades, experiencias, comunidades, culturas, políticas lingüísticas como desplazamientos continuos y globalizados. Nuevas formas de lenguaje y de producción de conocimiento en las diferentes áreas científicas surgen a partir de ese contexto en marcha, influenciando las elecciones locales-globales de los ciudadanos, según teorías recientes como las de Burbules y Torres (2000), Cilliers (2005), Gee (2004), Giroux (2005), Janks et al. (2014), Lankshear y Knobel, (2008, 2005), Brasil (2006), Todd (2010), entre otras. Los ciudadanos que buscan el IFE participan de tal contexto.

Ante esas dinámicas, las leyes de la sociedad y del mercado exigen velocidad y versatilidad de esos ciudadanos a punto de mezclar tiemposespacios de producción, recepción y redistribución de conocimiento, según se puede observar con el surgimiento de las nuevas tecnologías (CASTELLS, 2006; GEE, 2004; LANKSHEAR; KNOBEL, 2005, 2008). Se puede decir que los estudiantes de inglés sin acceso a una computadora o teléfono celular no están totalmente excluidos, una vez que leen textos producidos, distribuidos y consumidos vía tecnología, como por ejemplo las telenovelas, textos de revistas y periódicos, que se traspasan por el lenguaje multi-hiper-modal. A partir de ese concepto flexible del IFE, es conveniente repensarlo reconociéndolo también como una práctica social (STREET, 1984) a la luz de las nuevas demandas históricas y sociales. Es en ese escenario en constante cambio que la enseñanza de la lengua inglesa toma diferentes rumbos. El IFE, según Celce-Murcia (2001) y Celce-Murcia y Olshtain (2000), asume que la enseñanza de la lengua debe considerar dos aspectos: primero, las necesidades específicas del aprendiz en cuanto a su uso; segundo, la enseñanza de esta lengua puede y debe incluir los contextos socioculturales en los cuales el aprendiz la usará.

Se observa que tradicionalmente en el IFE las necesidades de los aprendices de inglés se justifican por las exigencias profesionales de negocios, ambientes técnicos y académicos, pero poco ha sido publicado sobre la comprensión del IFE como una práctica social compleja que va más 
allá de la práctica restricta a las habilidades de escuchar, hablar, leer y escribir en inglés. El IFE se está consolidando en diversos cursos universitarios con alumnos interesados en ingresar en el mercado laboral o en cursos de grado y posgrado mediante concurso y/o examen público.

De esa manera, las instituciones de enseñanza y sus profesores organizan cursos de IFE o adaptan programas afines ya existentes para atender a los intereses de un determinado grupo. Normalmente se escoge una habilidad para desarrollarla, por ejemplo, en cuarenta horas o más. En el caso de la lectura, toda la variedad de componentes lingüísticos (sintaxis, morfología, semántica), pragmáticos y discursivos abarca no solo una determinada área de conocimiento como turismo, medicina, ingeniería, derecho, educación, tecnología, sino también como se concibe esa misma área.

Para un mejor aprovechamiento del curso, y observando el grado acentuado de heterogeneidad del grupo, se enfatizó la enseñanza de naturaleza colaborativa y participativa, con interacciones organizadas en parejas de aprendices, pequeños grupos e individualmente. Es desde esa perspectiva de práctica pedagógica colaborativa que ha sido impartido el curso que a continuación se describe. Se presentan los presupuestos de la literacidad que dan base al curso de extensión y la experiencia obtenida, así como la contextualización del curso, los resultados de la experiencia, destacando como la literacidad crítica y los géneros híbridos pueden contribuir para los cursos de IFE y, para finalizar, algunas consideraciones para discutir con los interesados por el tema.

\section{Literacidad crítica: presupuestos que orientan la experiencia en cuestión}

Autores como Muspratt, Luke y Freebody (1997) adoptan la literacidad crítica clasificándola como literacidad visual, literacidad multicultural, literacidad mediática y literacidad de la informática. Ya Lankshear y Knobel (2008) conciben las nuevas literacidades para referirse a las diferentes formas de lenguaje y de construcción de conocimiento provocados por el medio digital, o sea, la literacidad digital. Takaki (2012) utiliza el término literacidades en forma plural para resumir los tipos de literacidad anteriormente mencionados, traspasados por la criticidad, al mismo tiempo en que sugiere una compleja red de interconexiones entre todos los tipos 
de literacidad antes mencionados. De acuerdo con el modelo ideológico de literacidad postulado por Street (1984), la literacidad crítica se refiere a una práctica social de lenguaje en la que los interlocutores utilizan formas de lenguaje de diversas fuentes y recursos para construir y negociar significados con una variedad de interlocutores. Cuestiones de raza, etnia, sexualidad, género y diversidad cultural intensifican la lucha por intereses propios en un juego de lenguaje que mezcla ideologías, paradojas y relaciones dinámicas de poder.

El mencionado autor enfatiza la necesidad de que constantemente se haga uso de lo que se denomina reflexividad, por medio de la cual es posible reflexionar de forma dialógica respecto a las interacciones que emergen de una determinada práctica social. Street (1984) se alimenta de la fuente freiriana en la proporción que destaca el poder de transformación de la condición social del interlocutor mediante la capacidad de renegociar significados en la lucha por el poder. Aunque Freire $(1998,2005)$ no haya utilizado el término literacidad, su concepción de lenguaje traspasa las prácticas sociales. Estas posibilitan a los agentes, usuarios del lenguaje, transformar su propia condición social, es decir, promover acciones y actividades con elecciones informadas que tengan en cuenta la movilidad social. En ese sentido, se construye una relación, la del yo-otro(s), que presupone una especie de caleidoscopio ético. Este implica la inconmensurable responsabilidad que ese Yo tiene con relación al otro, no solamente en el contexto de cada uno, sino también en la sociedad como un modo de vida, de acuerdo con Levinas (1978) y Caputo (1993).

Cervetti, Pardales y Damico (2001) y Janks et al. (2014) amplían el concepto de literacidad crítica comparándola con la lectura crítica. Esta última, centrada en el humanismo liberal, busca la repetición y reproducción de la intención del autor de un determinado texto. Esa vertiente se pauta en la creencia de la garantía de una verdad por detrás de las apariencias de un texto, reforzando, de esa forma, la idea principal del texto. Preguntas típicas de esa opción incluyen: ¿Cuál es la intención del autor?, ¿Cuál es la idea central del texto?

La literacidad crítica asume lenguaje, identidad, conocimiento, cultura, poder, enseñanza-aprendizaje y realidad como nociones que se modifican y se presentan ideológicamente porosas, motivo por el cual están sujetas a constantes reinterpretaciones. El lenguaje no capta completamente la realidad, reforzando el pensamiento de Bakhtin (1999), debido a su 
naturaleza heterogénea y dinámica. Por otro lado, el lenguaje construye y reconstruye realidades de forma pluralizada. El conocimiento siempre se reconstruye localmente y nunca está listo como un producto concluido. Es, ante todo, un proceso incompleto y generador de constantes modificaciones influenciado por una variedad de valores culturales, políticos, económicos y sociales que también están sujetos a cambios. Cervetti, Pardales y Damico (2001), Janks et al. (2014), McLaughlin y DeVoogd (2004) van más allá de meras preguntas, sugiriendo, por otro lado, el término cuestionamientos. En ese sentido, retoman la agencia del usuario del lenguaje difundido por Freire (2005) mediante el ejercicio de desafíos de interpretaciones ya consagradas (y legitimadas por grupos hegemónicos) para proceder a un raciocinio que reconstruya otras visiones/interpretaciones/versiones históricamente silenciadas y, tal vez, rompan con las relaciones rígidas de poder. Veamos algunos ejemplos de cuestionamientos que permitieron las discusiones de los textos en el curso en cuestión:

a) ¿Quién cuenta la historia?

b) ¿A nombre de quién se cuenta la historia?

c) ¿Qué otras voces/perspectivas/realidades faltan?

d) Un texto alternativo ¿qué versión de la historia contaría?

e) ¿Se incluye su realidad en ese texto? ¿Por qué?

f) ¿Cuáles son las implicaciones de cada interpretación de la historia?

La literacidad crítica requiere un profesor que cultive el espacio para diálogos donde la voz del alumno y su creatividad sean valoradas tanto como su desarrollo lingüístico. La última pregunta caracteriza la literacidad crítica como una oportunidad para que el alumno piense respecto a las consecuencias locales y globales complejas de posicionarse de una forma u otra en un determinado momento de su construcción crítica de conocimiento.

Esa manera crítica de construir conocimiento considera las diferentes formas de lenguaje, presente también en el lenguaje digital. La intensidad de usos de tecnología de penúltima generación siempre se proyecta en el devenir de las actividades diarias de muchos aprendices que han generado una profusión de géneros transmutados en la concepción de Bakhtin (1999) y Swales (1990). Dicho de otra forma, un género presenta enunciados 
relativamente estables, pero no fijos. Eso hace posible la creación de géneros híbridos como telemensajes, mensaje de texto por teléfono celular, videoconferencias, charla virtual, correos electrónicos y clases virtuales. Es a partir de esa base que se utilizó en este artículo los géneros híbridos.

Una de las consecuencias del trabajo en el medio digital es exactamente la dilución de fronteras rígidas entre la oralidad y la escritura, lo que provoca el surgimiento de géneros híbridos y desafía la capacidad lectora de quien los articula. Una composición compleja de elementos colabora para una mayor integración y, al mismo tiempo, dispersión entre semiosis, o sea, un juego complejo y dinámico, compuesto por signos verbales, sonidos, imágenes y animaciones con determinado uso y funcionalidad, según presentan Kress y van Leeuwen (1996) y Manovich (2001). Es el caso de la publicidad, anuncios y propagandas, géneros que han ganado destaque por su frecuencia en, por ejemplo, exámenes públicos (cuando la lengua inglesa está presente), en los cuales los candidatos tienen que leer e interpretar textos acompañados de imágenes (caricaturas animadas e historietas).

Se observa, así, que se usa con frecuencia textos extraídos de revistas, periódicos, libros y páginas web. De esa manera, el lenguaje se vuelve cada vez más plástico y el espacio digital se caracteriza por ser semejante a la silicona, en la concepción de Snyder (2008), Lankshear y Knobel (2005) y Gee (1996, 2004). ¿Qué cambia respecto a los aspectos estructural, formal, discursivo, sociohistórico e ideológico de un determinado texto leído en un soporte digital y del "mismo" texto leído en papel? Los procedimientos didácticos para la lectura de textos en el espacio virtual-real, noción adoptada por Castells (2006), suscitan nuevas reflexiones en cuanto a la enseñanzaaprendizaje de IFE. Se enfatiza la no linealidad de la lectura, pues se ofrece una multiplicidad de caminos al lector. La presentación de textos digitales no es neutra, o sea, está construida a partir de posicionamientos ideológicos de quien los crea y los aloja, reservadas las limitaciones tecnológicas (BRAGA; BUSNARDO, 2004).

Es en ese sentido que teóricos como Freire (2005), Cervetti, Pardales y Damico (2001), Cope y Kalantzis (2000), Janks et al. (2014), Brasil (2006), Monte Mór (2007, 2009), Pennycook (2010), Prinsloo (2005), Rajagopalan (2003), Street (1984), entre otros, sugieren la inclusión de lecturas y procedimientos de lectura que correspondan a las nuevas demandas de lo cotidiano en el ámbito profesional de los aprendices. Está en las manos del profesor y del aprendiz-híper lector de cursos de IFE enfrentar esos desafíos. 


\section{Contextualización del curso de extensión: Taller de IFE: lecturas para el presente-futuro en el mundo contemporáneo}

El objetivo general del curso de extensión fue desarrollar capacidades múltiples y estrategias para la lectura de diversos tipos de géneros textuales. De acuerdo con Swales (1990), este objetivo es alcanzable al planificar conjuntamente actividades y ejercicios variados relacionados con una situación de comunicación específica. La elección de textos se realizó con base en las constantes e informales solicitudes de los aprendices de diferentes cursos. Sus necesidades e intereses en común indicaban el trabajo con textos que integrasen el lenguaje verbal y no verbal utilizado en exámenes públicos, con ejercicios interpretativos y dirigidos al área de negocios (administración, economía, comercio, ingeniería, prestación de servicios, publicidad, tecnología, turismo, ciencia, salud, literacidad y educación). Algunos aprendices enfatizaron las dificultades encontradas en sus experiencias con exámenes que presentaban textos literarios o mediáticos con caricaturas, tiritas cómicas e imágenes demandando interpretación y no respuestas objetivas.

El objetivo específico estuvo centrado en la práctica de la lectura, análisis e interpretación de textos, de acuerdo con la concepción de lectura como práctica social, según Celce-Murcia y Olshtain (2000), Cope y Kalantzis (2000), Freire (1998), Gee (1996), Muspratt, Luke y Freebody (1997) y Street (1984). Es decir, se manejó la lectura como construcción de posicionamientos ideológicos y políticos y no meras interacciones entre autor, lector, texto y contexto. Para tanto, se tomó en cuenta el autor, el lector, el texto y los contextos de producción y de recepción. En ese sentido, se trata de un curso de extensión de vanguardia por tener como base las recientes teorías de literacidad y la práctica del IFE de forma complementaria como necesidad en la sociedad actual, que es cada vez más caracterizada por cambios y dotada de una intensa red de proliferación de heterogeneidades, según indica Castells (2006).

Más detalladamente, los objetivos específicos fueron:

1. Comprender que existen heterogeneidades socioculturales en las formas de comunicación entre las comunidades y en su seno que dependen del contexto donde el conocimiento se construye y se reconstruye;

2. Estimular diferentes interpretaciones críticas acerca de un determinado texto, considerando su multi-híper-modalidad y discutir las implicaciones locales-globales de diferentes posicionamientos respecto a ese texto; 
3. Desarrollar estrategias autónomas mediante la asociación entre elementos verbales y no verbales; expandir la capacidad de prever formas y contenidos del texto en cuestión, los cuales puedan orientar procedimientos de construcción de sentidos de la perspectiva del autor y del lector inmersos en contextos específicos; inferir ideas a partir de títulos, palabras-clave y uso del diccionario monolingüe.

La metodología de esa propuesta es de naturaleza cualitativa y exploratoria considerando las contingencias como las necesidades señaladas por los aprendices durante el curso y no solo en el comienzo del proceso de aprendizaje. También se toman en consideración las intersubjetividades de los participantes como una manera de interpretación sin que esta sea la única posible. Las clases fueron expositivas y participativas, en las cuales tanto los aprendices como el profesor interactuaban analizando los usos de determinadas estructuras y el vocabulario dirigido a la construcción de significados, reapropiación de interpretaciones ya validadas socialmente con la inclusión de otros valores culturales locales. En ese curso se utilizaron textos con propósitos, composición (lingüística e ideológica) y soporte diferenciado (papel, pantalla digital), cada cual con sus especificidades e implicaciones en la vida diaria de los aprendices-usuarios del lenguaje. Para la evaluación, estaban previstos dos exámenes destinados a la lectura y a la interpretación de textos.

El curso contó con la participación de los miembros de la comunidad interna de la UFMS (Universidad Federal de Mato Grosso do Sul) y participantes que viven en Aquidauana - MS y alrededores. La mayoría de los jóvenes son estudiantes de las carreras de Filología, Administración, Biología, Geografía y Turismo y una alumna del programa de doctorado en Lingüística Aplicada. Tales participantes demostraron familiaridad con el uso de Internet, pero con poco tiempo para comunicarse utilizando la lengua inglesa.

La justificativa del curso se basa en las respuestas a las encuestas de los interesados que señalaban la necesidad de leer bibliografías de las asignaturas de sus cursos en inglés, de presentarse a concursos públicos, viajar y prepararse para comunicarse con extranjeros, dada la peculiaridad turística de la región. Ellos se juzgaban capaces de leer razonablemente bien en inglés, pero carecían de prácticas más amplias y consistentes. Se ha decidido no aplicar una prueba de clasificación por nivel de proficiencia de la lengua inglesa, de acuerdo con Morin (2004), quien defiende que una 
reforma en la enseñanza requiere la ruptura de la linealidad del pensamiento. El cuadro de participantes se completó con la instructora responsable por este curso y el apoyo del Departamento de Filología de la UFMS, del Campus de Aquidauana. Para la obtención de datos se utilizaron respuestas escritas y orales de los participantes, provenientes de los textos y actividades, apuntes de clase, de fragmentos de conversaciones fuera de la clase y contestación a preguntas sobre la evaluación del curso.

\section{Resultados de la experiencia relatada: cursos de IFE complementados por la literacidad crítica y los géneros híbridos}

Más que la mera conciliación o complementación del IFE por la literacidad, es importante destacar el cambio epistemológico que la transformación de un programa dirigido al IFE requiere. Uno de esos cambios se basa en la elección de la concepción de lenguaje, conocimiento, cultura, realidad e identidad. Dependiendo de tal concepción, podrán seguir diferentes tipos de formación del ciudadano. Al asumir una concepción de lenguaje como heterogénea y opaca, habrá más oportunidades para que el aprendiz reconstruya constantemente otras interpretaciones (BAKHTIN, 1999).

De acuerdo con Bakhtin (1999), como sugerencia de opciones de géneros híbridos, se podrá utilizar en un curso de IFE los géneros concebidos, directa o indirectamente, mediante medios digitales como caricaturas, anuncios, mensajes de texto, folletos, artículos de opinión, vídeos de YouTube para trabajar como una forma de estimular en el aprendiz la percepción de que la lectura solo es lectura cuando hay un lector activo capaz de construir y reconstruir significados permanentemente a partir de la relación de su contexto con el contexto del autor y con toda la multi-hípermodalidad que es inherente al lenguaje.

Esa actitud de lectura por medio de la literacidad crítica y los géneros textuales híbridos traspasados por el lenguaje multi-híper-modal permite comprender cómo un determinado texto puede suscitar interpretaciones que consideren el lugar social e institucional sobre el cual el autor escribe, su estilo y sus conceptos de lenguaje, conocimiento, identidad, cultura, realidad, lectura; la naturaleza del contenido (tópico literario, jurídico, publicitario, científico, religioso en sus diferentes manifestaciones); el nivel de lenguaje, (dialectal, culto, formal, semiformal, informal; mecanismos de cohesión, 
nominal, verbal, conexión, modalización, períodos, léxico); el contexto en el cual el género está inscrito (solemne, público); la naturaleza de la relación entre los participantes (íntima o distante, nivel sociocultural, formación); la naturaleza de los propósitos de las actividades desarrolladas, es decir, el propósito social del texto focal. La consciencia de tales factores podrá contribuir a prácticas de lectura más amplias y transformar los análisis y las interpretaciones sociales e históricos con la perspectiva de ampliar las visiones de mundo.

Se observa que las estrategias de esa naturaleza podrán viabilizar la práctica de lectura con la inserción de una variedad de ejercicios y actividades relacionadas con un determinado texto. De ese modo, cuestiones y preguntas de carácter más subjetivo y cuestiones objetivas, como las de múltiple elección, pueden ser complementarias. Es fundamental observar las sutilezas por parte de quien elabora las cuestiones para aproximar autor, texto, lector, actividad referente al texto y contextos (momento histórico de producción del texto y de construcción de sentido a partir del texto focal). La tesis subyacente a la propuesta de enseñanza-aprendizaje de IFE, concebida como una práctica social (STREET, 1984), podrá facilitar la expansión de interacción entre los constructores de conocimiento y los textos. Aunque se enfrenten con textos pertenecientes a géneros y/o formas de lenguaje hasta entonces desconocidas, los aprendices, en esta experiencia, fueron capaces de articular sentidos con más autonomía, según sugieren Freire (1998) y Paiva (2005). Esto es lo que se detalla a continuación.

Es conveniente destacar que la metodología adoptada tiene previstas contingencias y la necesidad de ajustes en el programa preestablecido. Tal vez la idea de escuchar a los participantes durante todo el curso y de permitir hacer modificaciones indeterminadas a partir de la coautoría de los participantes pueda añadir una nueva percepción a los programas de IFE. De esa manera, uno de los textos utilizado en el curso de extensión, ya que el grupo solicitó la utilización de textos y actividades que mesclaran lenguaje verbal y no verbal y que les exigieran construcciones críticas de sentidos, fue un vídeo de YouTube intitulado Can Miles tackle the digital divide? (CAN MILES..., 2008). Se destaca que no se podría trabajar con temas específicos sólo de una carrera debido a la heterogeneidad de las licenciaturas presentes en el grupo. Respecto al vídeo, el protagonista se divide en dos: chico A, que desarrolla múltiples capacidades y se prepara para un futuro promisorio, crece en un ambiente de fácil acceso a la Internet; chico B, que 
se limita a hacer las tareas escolares tradicionales y pasa el resto del tiempo desocupado y distante de las redes sociales, con ninguna o escasa posibilidad de prepararse para el futuro. Se trata de una producción que, en el objetivo de convencer al espectador de que la inclusión digital es urgente, acaba por reforzar la dicotomía rígida entre estar o no estar incluido en la sociedad digital, como si hubiese solo un concepto de ciudadanía que dependiese exclusivamente de tener acceso a la Internet.

En ese vídeo, no se discutió cómo los jóvenes están interpretando y haciendo uso crítico de artefactos culturales producidos y diseminados por el espacio digital, tampoco las implicaciones de tales interpretaciones en la educación. Se realizaron discusiones sobre las cuestiones que tenían en cuenta la comprensión general del vídeo y de informaciones más específicas mediante preguntas como: ¿Cómo clasificas ese texto/género? ¿Cuál es el tema que predomina en el texto? ¿Cuál es el objetivo de las experiencias conducidas por el narrador? ¿De acuerdo con el vídeo, cuáles son las diferencias entre el chico A y el chico B? ¿Qué recursos utilizabas para comprender los diálogos que no entendías? Mencionas algunas de las profesiones que requieren el uso de computadoras. ¿Qué frase indica que millones de niños no tienen acceso a la Internet?

Como ejemplo de preguntas para el desarrollo de la literacidad crítica, se propuso:

a) Evalúa los recursos utilizados por el productor de esta película.

b) ¿Cómo los lectores se benefician de ese vídeo que acabas de ver?

c) ¿Cómo esa película desafía tu pensamiento?

d) ¿De qué forma se puede divulgar la idea de que el medio digital refuerza la división social? Considera las implicaciones educativas de tus elecciones (ej.: vídeo, carta al productor, foro en línea, propaganda, entrevista).

e) ¿Es posible sacar provecho de esa actividad para promover movilidad en tu vida? Movilidad: ¿eso es lo que deseas?

La mayoría de las respuestas destacó la división social que la falta de acceso a la banda ancha provoca. Algunos comentarios fueron:

P1: El vídeo muestra que si el niño, el joven, no tiene acceso a Internet no va a tener oportunidades en la vida. La Internet es imprescindible, ¿verdad? Me parece que es una alerta a los padres, al gobierno. ¿Y quién no tiene acceso a la computadora, cómo va a competir? (Traducción del autor) 
P2: No me siento conectada con el mundo sin Internet; si paso un día sin ver mis correos electrónicos, me siento mal; no consigo vivir sin estar en la red; quien no esté familiarizado con Internet se va a quedar fuera; pienso que uno solo consigue movilidad si tiene conexión con el mundo exterior. El acceso es todo. (Traducción del autor)

El refuerzo de las dicotomías parece prevalecer en el pensamiento de esos jóvenes que son directamente influenciados por su lugar de enunciación, concepto elaborado por Bhabha (1994), o sea, los lugares sociales donde los alumnos se posicionan y construyen saberes relacionados con el tema en discusión, como leer e interpretar los artefactos producidos y divulgados por la Internet, sigue siendo una cuestión abierta para una formación más crítica. Una de las estrategias utilizadas para promover desconstrucciones fue la utilización de preguntas inspiradas en Janks et al. (2014) como: a) ¿Cuál es el tema? b) ¿Qué opinas respecto a este tema? c) ¿Por qué piensas de esta forma? d) ¿Qué piensan otras personas de distintas comunidades sobre este tema? e) ¿Quién sería un lector que resistiría a los valores que el texto presenta? f) ¿Qué diría un lector resistente sobre lo que no se ha incluido en el texto? g) ¿Quién se beneficiaría con las decisiones que el autor hizo en términos de uso de lengua, imágenes y otros recursos semióticos? h) ¿De dónde surgen las diferencias contextuales? i) ¿Qué consecuencias hay en la sociedad cuando las diferencias lingüísticas y socioculturales no se respetan? Creo que se necesitan más prácticas de los aprendices sobre esas reflexiones con énfasis en la desconstrucción de polarizaciones cristalizadas por la sociedad en la formación ciudadana (DERRIDA, 1997).

\section{Construcción de sentidos}

Leer el mundo y las palabras con otros ojos es lo que Freire (2005) recomendó para que los ciudadanos transformen la propia condición social, propiciando una menor desigualdad en el mundo y, por lo tanto, mayor inclusión social con ética. Morin (2004) retoma esa vertiente y sugiere que la reforma social requiere una reforma del pensamiento. Pensamiento que muchas veces está acostumbrado con formas lineares de producción de conocimiento y que termina por encontrar dificultad al articular la simultaneidad de estructuras y vocabulario de determinados textos. No es que se pueda prescindir de la linealidad, de la gradación en niveles que van de uno a diez (libro básico hasta avanzado, serie I hasta V, por ejemplo) y el diseño de 
currículos, pero la consideración de otros sistemas de enseñanza-aprendizaje de lenguas de forma contingente, colaborativa y dinámica pueden sacar provecho a favor de la inclusión de aprendices con otros estilos y actitudes. The New London Group (1996) argumenta que "el papel de la pedagogía es desarrollar una epistemología de pluralismos que ofrezca el acceso sin que las personas tengan que borrar o abandonar diferentes subjetividades". La importancia del desarrollo de la percepción crítica, según Cervetti, Pardales y Damico (2001), Cope y Kalantzis (2000), Janks et al. (2014), Lankshear y Knobel (2005, 2008), Souza (2004), Monte Mór (2009, 2007) y Street (1984), entre otros estudiosos, está en la contribución para la reconstrucción de identidades, subjetividades, narrativas, relaciones de poder y realidades en la esfera social aliada al trabajo de exploración del texto, en una acepción amplia, mediante preguntas que involucren las reflexiones mencionadas anteriormente, así como las que enfoquen el entendimiento del uso de las estructuras, gramática y vocabulario, que contribuyan a la ampliación de las prácticas de autoría de sentidos por parte de los participantes.

En ese curso, se observó que la dificultad de una participante estaba directamente relacionada a su hábito de entender palabra por palabra para después ocuparse de la comprensión del texto leído o visto. El desafío para esa práctica incluyó la opción de estar atentos a lo que le era familiar en el título, las estructuras, las palabras clave e imágenes para proceder a las asociaciones, inferencias y previsiones que pudiesen conducirle a una construcción acerca de la temática sugerida por el texto que leyó o vio.

A partir de una contribución teórica postcolonial, Festino (2007) define literatura como un encuentro de culturas que le permite al aprendiz probar diferentes acentos, narrativas, modos de vivir, consideradas lecciones por las cuales ampliamos nuestro conocimiento, una vez que las experiencias de personajes traen otras versiones de la historia oficial legitimada por imperialistas eurocéntricos. ¿Por qué no sacar provecho de esa rica fuente para componer también la lista de alternativas en cursos de IFE transdisciplinarios, de acuerdo con orientaciones de Signorini y Cavalcanti (1998)?

De esa forma, en el afán de ofrecer la oportunidad para que los aprendices participasen de las decisiones sobre las elecciones de los materiales y asuntos a tratar, en una de las clases se les preguntó sobre la marcha del curso y contestaron que les gustaría leer algo que no tuviera 
relación directa con su área de estudios. "Alguna cosa que nosotros podamos leer por placer, sin relación con nuestras áreas, pruebas, concursos”, dijo una alumna. Considerando que en el comienzo del curso, esa misma alumna había realizado un examen y había presentado dificultad en trabajar con textos literarios, se ha elegido, dentro del género cuento, el título "Death of a Boy" de Chinua Achebe. Ese cuento deriva de su obra, el romance Things Fall Apart. La elección en aquel momento fue oportuna para la problematización de epistemologías y ontologías en conflicto.

La clase, según ya comentado anteriormente y según la comprende Pratt (1991), es una zona de contacto donde las relaciones complejas de valores y costumbres culturales locales se chocan con otros valores no locales, lo que genera el análisis de las propias presuposiciones y de las lecturas del cuento en cuestión. Surgió de ahí la dificultad de redefinir comunidades sin que estas perdiesen sus identidades en medio a la expansión del hibridismo lingüístico-cultural de forma contextualizada, como Souza (2004) subraya. A continuación, un breve resumen del cuento.

Se trata de una historia típica de la sociedad Igbo/Ibo, de Nigeria. Cuando una mujer era asesinada, al viudo se le concedía una mujer y a Okonkwo, jefe del clan, un niño para que él lo criara. Por orden del oráculo, ese niño, Ikemefuna, debería ser sacrificado. Se creía que la muerte de un niño evitaría la muerte de muchas personas en aquella sociedad. De esa manera, Ikemefuna fue sacrificado en la floresta, según el ritual religioso, por un grupo elegido y por el propio padre que lo había criado, Okonkwo, que había resistido hasta el último momento. Perturbado toda la vida por el hecho de que su padre no había tenido títulos y, por lo tanto, estaba desprovisto de prestigios y debilitado ante los ojos de aquella sociedad, Okonkwo ejecuta el acto mortal abreviando la vida de Ikemefuna por miedo a ser visto como una figura frágil.

Los participantes leyeron el texto en inglés para empezar la discusión. Algunas ideas (fear, pride, father's role, masculinity, the Oracle, the local values, the historical context) se presentaron para asumir el siguiente interrogante: What has most called your attention in the short story? Why?

En el ejercicio subsecuente, se debería trabajar con cuestiones más especificas: How is Ikemefuna feeling at this point of the story? And before? What sentence illustrates his state of being in a pluralized way? How does the author establish the contrast between such state of being? 
La última lista de preguntas fue elaborada con el propósito de trabajar el uso de although en una frase y, a partir de esta, la construcción de la frase: Although he had felt uneasy, he was not afraid now. Las preguntas encaminadas fueron: How do you classify words like although? What's the meaning of although in this context? How many clauses are there in this sentence? Can you start this sentence from the second clause without changing its meaning? Después de la discusión y aclaraciones lingüísticas, los participantes realizaron el siguiente ejercicio: Make a list of words or phrases you know to establish contrasts of ideas. En seguida, se procedió a la práctica del uso de tales conjunciones a partir de construcciones de frases que revelasen algo sobre su familia. Se les aclararon las dudas lingüísticas y se ha conciliado la exploración de textos acompañados de ejercicios de pronunciación, audición, estructuras y expansión de vocabulario necesarios, según convenía.

Pocos alumnos se arriesgaron a utilizar frases con las conjunciones practicadas anteriormente durante la discusión del cuento, lo que demandó la oferta de más ejercicios posteriormente. Las interpretaciones que más se destacaron en el grupo revelaron resistencia a comprender lo desconocido. La impaciencia de algunos para intentar colocarse en el lugar de enunciación de los personajes ganaba más sustentación con críticas rápidas, por decirlo así. El tenor de las críticas incidía en el episodio de la muerte del hijo encomendada por el dios de la comunidad local, que se entendió como un gesto inaceptable en cualquier religión. De esa forma, la pérdida de la credibilidad en el protagonista produjo antipatías con relación a la cultura local narrada en el cuento. El conflicto, generado por la lectura y atribuciones de sentidos al cuento, promueve la ventaja de reflexionar sobre educar para la complejidad, idea de Todd (2009), en el sentido de crearse otras versiones que no son necesariamente las del lugar común, como las estereotipadas. Veamos:

Ondina: Why Okonkwo (nombre raro), killed the boy? His religion permits this? Caique: Religion is dangerous, to kill children.

Perosa: I think it's kind of ritual because in Brazil, some religions have this practice to sacrifice people in the name of a God.

Vânia: But it's terrible! Your god killing this innocent child. You know what it is like to feel frustrated in life, when people compare you and your brother, for example, if he is more successful than you, what happens you don't accept the situation. Like here, Okonkwo uses his force to penalize somebody and this somebody is the child.

Paola: I don't' believe it's true. It's how can I say ficción? 


\section{P: Fiction. Why you don't believe in this story? \\ P: It is imagination of the writer.}

Aparentemente, la discusión giró alrededor del extrañamiento del comportamiento en la cultura ajena. La concepción de religión parece inhibir mayores debates y dificultar la comprensión del hecho de que la violencia también puede ser interpretada de manera diferente dentro de una misma cultura. En ese sentido, el procedimiento de desconstrucción elaborado por Derrida (1997) significa romper la frontera entre dos extremos en la forma de pensar y transitar por diversas culturas con una mirada flexible y abierta a otras formas de comportamiento y de coexistencia con las paradojas sociales. El riesgo impregnado en la mirada de esos aprendices parece impulsar la mera sustitución de polos aparentemente antagónicos: sustituir una cultura por otra, la del blanco europeo por la africana, en este caso representada por la comunidad Igbo. Se nota que existe producción de conocimiento en momentos como ese, pues la consciencia de que las culturas viajan, sin permanecer intactas cuando se enfrentan con otras, según señala Mignolo (2000), podrá ser más importante que sólo reconocer las diferencias.

Las cuestiones que suscitaron el debate que se menciona fueron las siguientes:

a) ¿Cómo observas las diferencias y semejanzas entre tu(s) cultura(s) y la(s) cultura(s) de Okonkwo?

b) ¿Cómo explicas y cómo Okonkwo explicaría las causas y orígenes del "estado de arte" de sus pensamientos?

c) ¿Cómo esas dos visiones, mencionadas anteriormente, se relacionan con otras visiones existentes en el mundo, en otras culturas y contextos?

d) ¿Cómo la comprensión de los dos contextos o más podrían negociar mundos mejores, $\mathrm{y}$ no iguales, para todos?

e) ¿Crees que la educación crítica reproduce o desafía conflictos lingüísticoculturales?

Canagarajah $(2008,2014)$ destaca el hecho de que la potenciación, el empowerment de perspectivas locales en relación a un texto, evento, enseñanza de lenguas, debe incluir la heterogeneidad coexistente dentro de una misma comunidad, presentando una especie de desterritorialización de culturas, de descentramiento de identidades con el surgimiento de otras normas y valores, ideas que coinciden con Todd (2009) y con Cilliers (2005). Siguiendo 
ese raciocinio, se puede inferir que los aprendices se presentaban en fase de transición de pensamiento ante lo desconocido. Esa actividad suscitó en dos participantes el deseo de discutir textos que ellos habían traído, ya sea en discusiones en parejas o en grupos de tres o cuatro. Debido al escaso tiempo de la programación, sugerí que escogiesen solamente un texto para trabajar.

Como en el caso del primer texto que trataba de un artículo científico que se iba a leer y discutir en la clase de postgrado de la alumna (doctoranda, en esa ocasión), los participantes votaron por el segundo. No tenemos por objetivo tratar detalladamente ese texto, solo informar que estaba en formato de cartel de propaganda de una posada que atiende la demanda de turismo local. El texto enfatizaba las cualidades de la posada y uno de los participantes cuestionó el uso de adjetivos seleccionados estratégicamente, ya que se había alojado en ese establecimiento en alguna ocasión, y criticó las formas como normalmente las propagandas de turismo prometen más de lo que ofrecen. En ese sentido, enfatizó una característica importante que presupone la participación de alumnos en las sugerencias que componen el contenido programático de cursos de esa naturaleza, o sea, vale la pena dividir el poder-saber con ellos, pues parece aumentar la autonomía en el propio proceso de aprendizaje.

En otro momento, se solicitó que los participantes del curso interpretasen algunas obras del joven artista Tony Albert, destacando múltiples tipos de literacidad, es decir, visual, multiétnica y crítica. Para la formación en ciudadanía, es fundamental que el aprendiz de este siglo tenga la oportunidad de desarrollar habilidades referentes a la literacidad visual crítica. Los nuevos medios, inteligentemente concebidos, representan un espacio interesante en que multimodalidades, culturas, identidades y realidades convergen y divergen. En las visiones de Baker (1991), Souza (1997), van Leeuwen (2008), las imágenes no son meras decoraciones de textos verbales, sino narrativas antropológicas complejas que influyen en la concepción de mundo y cómo lo articulan los ciudadanos. La relación entre el lugar de enunciación del productor de las imágenes, la imagen (como práctica social) producida y el lugar de enunciación del lector, que ahora es también autor de sentidos, hace posible el surgimiento de interpretaciones contextualizadas y variadas.

Retomando el tema obras, el citado artista explota cuestiones políticas, históricas, culturales y ambientales, con énfasis en la complejidad del binomio vida urbana y vida rural del aborigen, a quien se lo retrata desde la 
perspectiva de la ciudad en conflicto cultural con la llamada civilización del hombre blanco en Australia. En las expresiones urbanas, el artista cuestiona las representaciones estereotipadas y las manipulaciones del lenguaje creadas por la cultura occidental y abre espacio para reflexiones sobre la alienación y desplazamiento sociohistórico del aborigen en el contexto australiano.

Innovar la enseñanza de lenguas resulta dar oportunidades para que el alumno entienda que la comprensión de una obra artística puede desarrollar su capacidad crítico-interpretativa. O sea, el arte de Albert tiene que ser entendida como expresión de voces que claman por justicia social como consecuencia de la colonización europea en Australia, que generó pérdidas lingüísticas y culturales del lado aborigen. Las obras de dicho artista revitalizan el protagonismo de los aborígenes con sus prácticas sociales y el respeto al medio ambiente. El estilo kitsch (forma de arte deficiente y creativa) reverbera acciones por las emociones y se propone a invitar a los espectadores, las comunidades y las autoridades a hacer la diferencia, un detalle que normalmente no se suele ver en obras relativas a aborígenes. Una colección de materiales y objetos del día-día compone la Aboriginalia, término que el artista usa para describir los recursos de contenido ecológico con los cuales produce humor, esperanza, subvirtiendo el orden vigente al mismo tiempo que cuestiona la condición humana.

El lector puede apreciar en el vídeo de YouTube Albert, que abre la exposición en la Galería de Arte en Queensland y remite su obra al discurso del entonces Primer-Ministro australiano, Kevin Rudd, el trece de febrero de 2008, quien se disculpa, en nombre del país, por los problemas sociales generados por las políticas públicas del pasado con relación al caos y fragmentación de las familias de los aborígenes (SORRY... 2008). En esa obra, Albert inscribe el siguiente texto (FIGURA 1):

FIGURA 1 - Reconocimiento

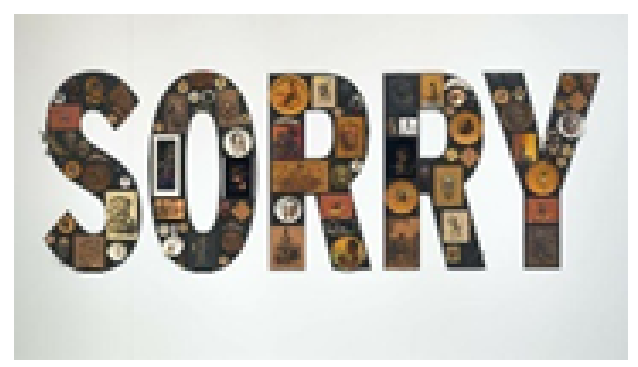

Fuente: News.com.au. 
Dentro de cada letra, hay fotografías de aquellos cuyas historias han revelado las causas malignas de las políticas australianas. Son imágenes de hombres, mujeres y niños que componen narrativas que claman por reinterpretaciones del público. El texto no celebra cambios significativos en cuanto al tratamiento prometido en relación con los aborígenes, sino más bien destaca formas de llamar la atención del público hasta que se tomen las iniciativas en la práctica.

Sobre las imágenes de dos aborígenes, tenemos (FIGURA 2):

FIGURA 2 - IntersubjetividadFuente: Murdoch University ${ }^{1}$
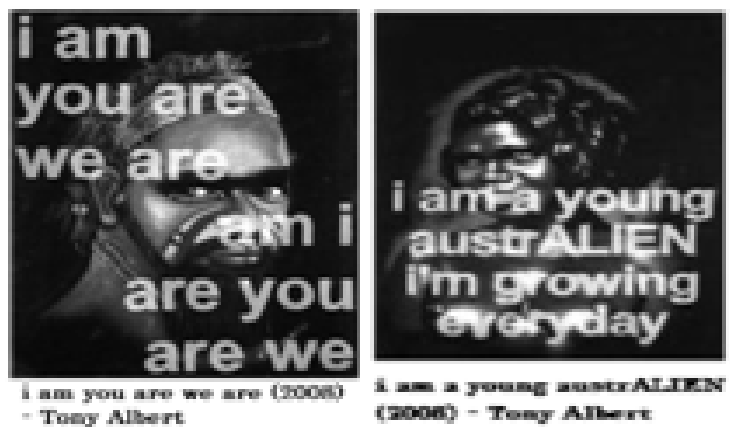

En la obra a la izquierda, lo que llama la atención es la estrategia de ruptura de las convenciones lingüísticas con el uso del pronombre i (minúsculo) en lugar de I (mayúsculo, como la norma culta de la lengua inglesa requiere), sugiriendo que los medios de comunicación y la historia oficiales dieron las espaldas a las cuestiones de identidad, lingüísticas y culturales de los pueblos nativos de Australia. El artista termina con un cuestionamiento sobre la legitimidad del poder del colonizador europeo, pregunta sobre la supuesta inferioridad del aborigen repitiendo el uso del pronombre $i$ minúsculo. Otra subversión se caracteriza por la ausencia de puntuación en los dos "versos" grabados en el rostro de un aborigen. Su mirada es irónica y dialógica y dirigirse a los interlocutores trae el capital identitario, histórico y cultural con perspectiva futura más positiva. A la derecha, tenemos la repetición de la estrategia de ruptura con la inscripción de la letra $i$ minúscula y el uso de la Y, mayúscula de esta vez, sobre el rostro de una joven aborigen. La construcción creativa y crítica está en austr ALIEN,

${ }^{1}$ Disponible en: https://bit.ly/3grzewD. 
un juego de letras que hace referencia a la desnaturalización del estereotipo lanzado por los europeos respeto a los aborígenes. La ironía se refuerza por la sonrisa de la joven en señal de apoderamiento, ya que todos los días crecen y se desarrollan calidades y acciones históricas que tienen que ser legitimadas.

Otra obra trae (FIGURA 3):

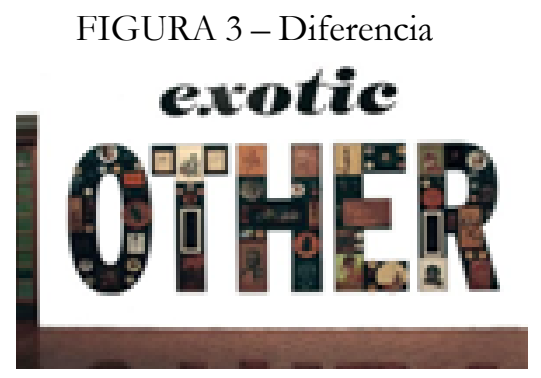

Fuente: MK Qianru Yang (blog). ${ }^{2}$

Dentro de la palabra OTHER, Albert pone las imágenes de niños, mujeres, rostros de hombres y libros que componen el discurso de protesta en nombre de la comunidad aborigen. En la letra $\mathrm{H}$, nuevamente se lee exotic OTHER, haciendo analogía con el sentido de austrALIEN, ya caracterizado anteriormente y que se repite en la obra a seguir, la del lado derecho, con la imagen de un joven.

Abajo (FIGURA 4), en la obra a la derecha, en el rostro de un señor, leemos:

FIGURA 4 - Género
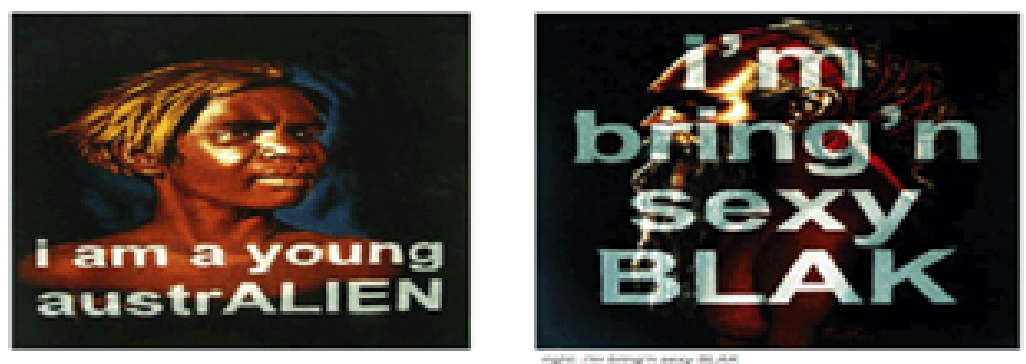

Fuente Andrea Geyer (Tumblr). ${ }^{3}$

\footnotetext{
${ }^{2}$ Disponible en: https://bit.ly/39SsvZV.

${ }^{3}$ Disponible en: https://bit.ly/2XnEXvT.
} 
El tema aquí es de la sensualidad y gana destaque con nuevas rupturas como bring'n y no la forma convencional bringing y $B L A K$ en caja alta y colores blancos para llamar la atención, en lugar de $B L A C K$. El fondo en color negro, el dorado y el marrón de los rostros y de los hombros contrastan con el resto, indicando que los repertorios multimodales reconstituyen las identidades locales con los movimientos incesantes del lenguaje, una información relevante a las literacidades críticas. Para la discusión, se propusieron las siguientes reflexiones: ${ }^{4}$

a) ¿Cómo esa comunidad se compara con otras comunidades en términos de desarrollo? ¿Cómo la ven las otras comunidades?

b) ¿Crees que tu comunidad debería "alcanzar" a las otras en algún aspecto? $¿$ Tu comunidad puede enseñarles a las otras y también aprender con ellas? ¿Cómo explicas los motivos, los orígenes de su pensamiento?

Tal vez, por no tener el hábito de interpretar textos de esa naturaleza, las interacciones fueron tímidas y reticentes. Los que verbalizaron posiciones se limitaron a decir que las obras eran interesantes y que impactaban al público. Expresaron la validez del trabajo del artista como una forma de protesta social y que eso también representaba principalmente la situación de muchos negros e indígenas en Brasil:

Dória: The pictures are interesting to impact the public. This happens in Brazil too, with blacks and indians, indigenas.

P: Yes, Paola?

Paola: I think it's a protest by the artist.

P: Why?

Vânia: They are people oppressed by society, the blacks in Brazil still feel discriminated, it's a problem.

Marconi: More protests are in musics.

P: What do you mean?

Marconi: In Brazilian groups like rap, poor protest against the governor. It's common.

Por esas contestaciones, se puede inferir que cuestiones de género, etnia, identidad, sexualidad, poder, tal vez hayan generado retroceso en las

\footnotetext{
${ }^{4}$ Estas preguntas se adaptaron de academia.edu/276974/Through_Other_Eyes por Vanessa Andreotti y Lynn Mário T. M. de Souza.
} 
discusiones, porque son cuestiones delicadas, por decirlo así, y ni siempre los alumnos se sienten a gusto para posicionarse por más tiempo en su discurso, pero esa es solamente una hipótesis que merece más investigación.

Dando continuidad a las consideraciones finales de este artículo, así como Monte Mór $(2007,2009)$ defiende, es necesaria una revisión de los programas de IFE por la literacidad crítica, por las metodologías de multihiper-lenguajes y de diferentes maneras de construcción de conocimiento y subjetividades con la inclusión de valores locales y epistemologías que valoricen el desarrollo lingüístico, sociocultural y educación crítica, representa una alternativa de extrema relevancia y viabilidad para introducir el aprendiz en el universo globalizado y digital de este siglo. Respecto a la evaluación de este curso, se les pidió a los aprendices que presentaran sus visiones, sugerencias y críticas para posibles reconstrucciones. Aparentemente, en la visión de los aprendices, se evidenciaron cambios en el estado de construcción de saberes al inicio y al final del curso:

Ondina: El curso me pareció excelente, estuvo a cargo de una excelente profesional, que no imparte metódicamente (sistemáticamente), sino que trabaja con dinamismo, buscando atender a las necesidades de los alumnos y llevarlos a una reflexión crítica en el aprendizaje. Obtuve más vocabulario en la comprensión de los diversos géneros literarios. Como sugerencia, creo que se debe divulgar más para una mayor demanda del curso. (Traducción del autor)

Perosa: Curso excelente, pues no enfoca solo traducción y reglas gramaticales, sino también el temperamento crítico que estimula la mente a reflexionar sobre otros aspectos que puedan ser relevantes al tema, incluso interpretar mejor el propio texto con conocimiento básico de la lengua. (Traducción del autor)

Solange: Pretendo, porque realmente lo necesito, sacar provecho de la Internet, hay como practicar inglés a través de las páginas web que yo vi, con ejercicios; YouTube ayuda a entender mejor el listening, es un hábito ir, hablar con alguien más de fuera por Skype. (Traducción del autor)

Caique: No podemos parar por aquí, si usted puede ofrecer otro curso lo voy a hacer, seguro, pero, mientras tanto, voy a buscar libros, Cds. (Traducción del autor) (Este discurso se compiló al concluir el curso)

Esas declaraciones señalan hacia la reconstitución gradual de las identidades y de los posicionamientos de los alumnos por medio de la práctica constante de lectura de textos con diferentes temáticas, diferentes 
modalidades lingüísticas que se han expresado en y por la lengua inglesa e hicieron posible la reconstrucción de sus saberes conectando las experiencias de sus vidas diarias y los desafíos mediante las reflexiones propuestas por el curso en cuestión.

Un alumno de Geografía hizo consideraciones interesantes sobre los aborígenes al elaborar un feedback escrito sobre este curso de extensión. Dijo que apreció las discusiones sobre los pueblos, identidades, memorias y conflictos sociales del mundo. Destacó que se acordó de los rostros en el trabajo de Tony Albert que "illustrate the fake identities of Aborigines in a situation that was created by the white European in Australia, who devastated their home, families and culture. But, I remember some faces were smiling back to the colonizers. A sign of discomfort to the Europeans. Tony Albert captured this ambivalence in the humans." La comprensión de este alumno muestra que leer la mirada es de suma importancia en las literacidades críticas. El humor en Tony Albert está exactamente en aprender la sutileza de la esperanza que el propio aborigen trae. Este valor de imagen compensa la supuesta inferioridad de $i$ en $i$ am y hace surgir otras posibilidades de construcción de sentidos. El contenido de la obra, el modo de presentarla y el contexto socio-histórico en el cual ella está inserida presentan una perspectiva en que el espectador tiene que problematizar. Re-imaginar otras miradas sobre la misma obra permite al alumno desnaturalizar y remodelar sus lentes y acciones con el objetivo de transformar sus propias literacidades críticas en un constante proceso de reflexión.

La concienciación de que los nuevos recursos tecnológicos pueden favorecer la autonomía del aprendiz en una creciente heterogeneidad de formas de practicar la lengua inglesa y relacionarse con el otro también mereció la atención en la visión de los aprendices. Es esa confluencia de diversidades con relación al tratamiento teórico-práctico que se propuso este curso de extensión, lo que permite que podamos pensar en nuevos formatos de cursos de IFE con otras miradas y renegociaciones de significados locales-globales en la formación de alumnos para una sociedad en constante transformación epistemológica compleja.

\section{Consideraciones finales}

Con este curso de extensión universitaria, los participantes tuvieron la oportunidad de practicar la lengua inglesa en diversos contextos de uso, 
destacando la construcción crítica de sentidos mediante discusiones a partir de temas considerados interesantes y relevantes para ellos. Hubo la preocupación de ofrecer un material lleno de cuestiones emergentes, como las multimodalidades presentes en las formas de comunicación de una sociedad digital. Durante el proceso de construcción de saberes se trabajaron cuestiones de lengua, identidad, cultura, poder y ciudadanía, contando siempre con el repertorio sociolingüístico y cultural de los participantes, su visión de mundo y ampliación de su objetivo interpretativo.

La orientación para la construcción de sentidos propició el encuentro de diferentes perspectivas mediante cuestionamientos importantes para la percepción de la localización social de los interlocutores y de las implicaciones que ese encuentro tiene respecto a la sociedad, además de discusiones y explicaciones del uso específico de insumos lingüísticos contextualizados. Las discusiones sobre temas no relacionados con los cursos de grado de algunos participantes terminaron por provocar momentos de mayor empeño y usos significativos de la lengua inglesa por su parte. Se concluye que las construcciones de subjetividades mediante los lenguajes multi-hiper-modales pueden complementar la programación de cursos de inglés con fines específicos.

Mediante la inclusión de textos sobre cuestiones complejas de cultura y lengua, los participantes sintieron la necesidad de buscar, autónomamente, otros medios de participación social en el mundo actual de la lengua inglesa. Al finalizar el curso, expresaron sentimientos de más confianza y seguridad para leer y construir sentidos en diversos ambientes de actuación. Ampliando las perspectivas, esta iniciativa podrá influenciar a otros en el afán de tomar decisiones fundamentadas, transformando las propias formas de existir y actuar según las capacidades múltiples demandadas por la sociedad digital.

\section{Referencias}

BAKER, C. Literacy Practices and Social Relations in Classroom Reading Events. In: BAKER, C.; LUKE, A. (ed.). Towards a Critical Sociology of Reading Pedagogy. Philadelphia: John Benjamins, 1991. v. 1, p. 161-190. DOI: https://doi. org/10.1075/pbns.19.11bak

BAKHTIN, M. Marxismo e filosofia da linguagem. São Paulo: Hucitec, 1999.

BHABHA, H. K. The Location of Culture. New York: Routledge, 1994. 
BRAGA, D. B.; BUSNARDO, J. Digital Literacy for Autonomous Learning: Designer Problems and Learner Choices. In: SNYDER, I.; BEAVIES, C. (ed.). Doing Literacy Online: Teaching, Learning and Playing in an Electronic World. Cresskill: Hampton, 2004. p. 45-68.

BRASIL. Ministério da Educação. Orientações curriculares para o ensino médio: linguagens, códigos e suas tecnologias. Brasilia, DF: Ministério da Educação, 2006. Disponible en: https://bit.ly/2XsmsGG. Acceso el: 22 agosto 2018.

BURBULES, N. C.; TORRES, C. A. Globalization and Education: Critical Perspectives. New York: Routledge, 2000.

CANAGARAJAH, A. S. (ed.). Reclaiming the Local in Language Policy and Practice. New York: Routledge, 2008.

CANAGARAJAH, A. S. In Search of a New Paradigm for Teaching English as an International Language. Tesol Journal, Hoboken, v. 5, n. 4, p. 767-785, 2014. DOI: https://doi.org/10.1002/tesj.166

CAN MILES Tackle the Digital Divide? [S. l.: s. n.], 2008. 1 vídeo (3 min). Publicado por el canal Elearning Foundation. Disponible en: https://youtu.be/BARWmnj7Aw. Acceso el: 4 oct. 2020.

CAPUTO, J. Against Ethics. Contributions to a Poetics of Obligation with Constant Reference to Deconstruction. Bloomington: Indiana University Press, 1993.

CASTELLS, M. A sociedade em rede. São Paulo: Paz e Terra, 2006.

CELCE-MURCIA, M. (ed.). Teaching English as a Second or Foreign Language. 3. ed. Boston: Heinle \& Heinle, 2001.

CELCE-MURCIA, M.; OLSHTAIN, E. Discourse and Context in language teaching. A Guide for Language Teachers. Cambridge: Cambridge University Press, 2000.

CERVETTI, G.; PARDALES, M. J.; DAMICO, J. S. A Tale of Differences: Comparing the Traditions, Perspectives, and Educational Goals of Critical Reading and Critical Literacy. [S.l.]: [s.n.], 2001. Disponible en: https://www. researchgate.net/publication/334372467_A_Tale_of_Differences_Comparing_ the_Traditions_Perspectives_and_Educational_Goals_of_Critical_Reading_ and_Critical_Literacy/link/5d25e94e92851cf4407535a3/download. Acceso el: 14 ago. 2020.

CILLIERS, P. Complexity and Postmodernism: Understanding Complex Systems. New York: Routledge, 2005.

COPE, B.; KALANTZIS, M. (ed.). Multiliteracies: Literacy Learning and the Design of Social Futures. New York: Routledge, 2000. 
DERRIDA, J. Of Grammatology. Baltimore: Johns Hopkins University Press, 1997. $441 \mathrm{p}$.

DUDLEY-EVANS, T.; SAINT JOHN, M. J. Developments in English for Specific Purposes: A Multidisciplinary Approach. Cambridge: Cambridge University Press, 1998.

FESTINO, C. G. Broadening the Social Contract Through the Literary Text. Critical Literacy: Theories and Practices, Nottingham, v. 1, n. 1, p. 90-99, 2007. Disponible en: https://bit.ly/3gtGPdQ. Acceso el: 13 agosto 2018.

FREIRE, P. Pedagogia da autonomia: saberes necessários à prática educativa. São Paulo: Paz e Terra, 1998.

FREIRE, P. Pedagogia do oprimido. Rio de Janeiro: Paz e Terra, 2005.

GEE, J. P. Situated Language and Learning: A Critique of Traditional Schooling. New York: Routledge, 2004.

GEE, J. P. Social Linguistics and Literacies: Ideology in Discourses. London: Taylor \& Francis, 1996.

GIROUX, H. Border Crossings: Cultural Workers and the Politics of Education. New York, London: Routledge, 2005.

HUTCHINSON, T.; WATERS, A. English for Specific Purposes: A Learning-Centred Approach. Cambridge: Cambridge University Press, 1987. DOI: https://doi. org/10.1017/CBO9780511733031

JANKS, H. et al. Doing Critical Literacy: Texts and Activities for Students and Teachers. New York: Routledge, 2014. DOI: https://doi.org/10.4324/9780203118627

KRESS, G.; VAN LEEUWEN, T. Reading Images: The Grammar of Visual Design. New York: Routledge, 1996.

LANKSHEAR, C.; KNOBEL, M. (ed.). Digital Literacies: Concepts, Policies, and Practices. New York: Peter Lang, 2008.

LANKSHEAR, C.; KNOBEL, M. New Literacies: Changing Knowledge and Classroom Research. Buckingham: Open University Press, 2005.

LEVINAS, E. Otherwise Than Being, or Beyond Essence, the Second Magnum Opus. Translation by Alphonso Lingis. Boston: Kluwer, 1978.

MANOVICH, L. The Language of New Media. Cambridge, MA: MIT Press, 2001.

McLAUGHLIN, M.; DEVOODG, G, L. Critical Literacy: Enhancing Students' Comprehension of Text. Foreword by Allan Luke. London: Scholastic, 2004. 
MIGNOLO, W. Local Histories, Global Designs: Coloniality, Subaltern Knowledges and Border Thinking. Princeton: Princetown University Press, 2000.

MONTE MÓR, W. Foreign Languages Teaching, Education and the New Literacies Studies: Expanding Views. In: GONÇALVES, G. R. et al. (org.). New Challenges in Language and Literature. Belo Horizonte: Fale/UFMG, 2009. p. 177-189.

MONTE MÓR, W. Investigating Critical Literacy at the University in Brazil. Critical Literacy: Theories and Practices, Nottingham, v. 1, n. 1, p. 41-51, 2007. Disponible en: https://bit.ly/3gtGPdQ. Acceso el: 4 oct. 2020.

MORIN, E. Saberes globais e saberes locais: o olhar transdisciplinar. Rio de Janeiro: Garamond, 2004.

MUSPRATT, S.; LUKE, A.; FREEBODY, P. (ed.). Constructing Critical Literacies: Teaching and Learning Textual Practice. Cresskill: Hampton, 1997.

NEW LONDON GROUP. A Pedagogy of Multiliteracies: Designing Social Futures. [S.l.]: [s.n.], 1996. Disponible en: https://www.researchgate.net/ publication/242352947_Multiliteracies_New_Literacies_New_Learning/ link/56b29ed708ae5ec4ed4b5883/download. Acceso el: 14 agosto 2018.

PAIVA, V. L. M. O. (org.). Práticas de ensino e aprendizagem de inglês com foco na autonomia. Belo Horizonte: Fale/UFMG, 2005.

PENNYCOOK, A. Language as a Local Practice. New York: Routledge, 2010. DOI: https://doi.org/10.4324/9780203846223

PRATT, M. L. Arts of the Contact Zone. Profession, New York, v. 91, p. 33-40, 1991.

PRINSLOO, M. The New Literacies as Placed Resources. Perspectives in Education, Centurion, v. 23, n. 4, p. 87-98, 2005. Disponible en: https://bit.ly/33oB11A. Acceso el: 22 agosto 2018.

RAJAGOPALAN, K. Por uma linguística crítica: linguagem, identidade e questão ética. Campinas: Pontes, 2003.

SIGNORINI, I.; CAVALCANTI, M. C. (org.). Linguistica aplicada e transdisciplinaridade: questões e perspectivas. Campinas: Mercado de Letras, 1998.

SNYDER, I. Literacy Wars: Why Teaching Children to Read and Write is a Battleground in Australia. Crows Nest: Allen \& Unwin, 2008.

SORRY, Kevin Rudd's Apology to “The Stolen Generation”. [S.l.]: [s. n.], 2008. 1 vídeo (3 min). Publicado por el canal Channel 10. Disponible en: https://youtu. be/b3TZOGpG6cM. Acceso el: 22 agosto 2018. 
SOUZA, L. T. Hibridismo e tradução cultural em Bhabha. In: ABDALA JÚNIOR, B. (org.). Margens da cultura: mestiçagem, hibridismo e outras misturas. São Paulo: Boitempo, 2004. p. 113-134.

SOUZA, L. T. Voices on Paper: Multimodal Texts and Indigenous Literacy in Brazil. Social Semiotics, Abingdon, v. 13, n. 1, 29-42, 1997. DOI: https://doi. org/10.1080/1035033032000133508

STREET, B. Literacy in Theory and Practice. Cambridge: Cambridge University Press, 1984.

SWALES, J. Genre Analysis: English in Academic and Researching Settings. Cambridge: Cambridge University Press, 1990.

TAKAKI, N. H. Letramentos na sociedade digital: navegar é e não é preciso. Jundiaí: Paco Editorial, 2012.

TODD, S. Toward an Imperfect Education: Facing Humanity, Rethinking Cosmopolitanism. New York: Routledge, 2009.

VAN LEEUWEN, T. New Forms of Writing, New Visual Competencies. Visual Studies, Abingdon, v. 2, n. 3, p. 130-135, 2008. DOI: https://doi. org/10.1080/14725860802276263

Data de submissão: 05/04/2019. Data de aprovação: 16/10/2019. 